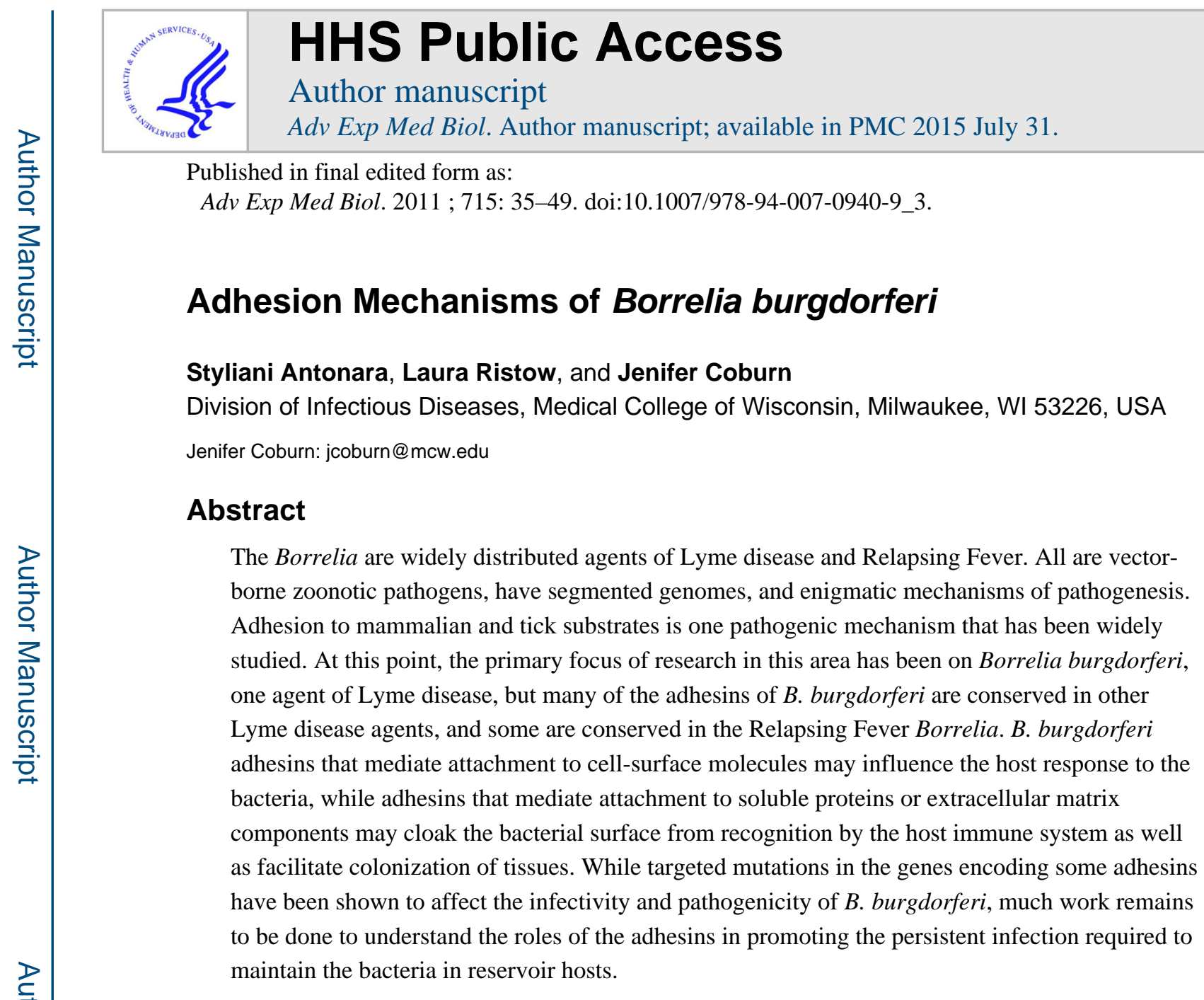

\title{
3.1 Introduction
}

The spirochetes in the genus Borrelia cause relapsing fever and Lyme disease. This chapter focuses on the Lyme disease agents, and primarily on a single species, Borrelia burgdorferi, as this organism has been the primary object of study and the focus of relatively recent advances in approaches to understanding how these organisms cause infection and, in susceptible hosts, disease. $B$. burgdorferi is normally maintained in mammalian reservoir hosts and tick vectors, and the mechanisms by which $B$. burgdorferi causes infection remain poorly understood. In fact, how $B$. burgdorferi causes disease has been more thoroughly characterized by manipulation of the host rather than of the bacterium. Relatively recent advances in the genetic approaches that are possible in this organism have started to turn this tide, and have been applied to understanding the in vivo significance of the numerous adhesins that have been identified through in vitro studies.

There are a few oddities of $B$. burgdorferi that warrant introduction. First, the genome is relatively small, at approximately $1.5 \mathrm{Mbp}$, but is highly segmented, as approximately one third of the annotated genes are encoded on circular and linear plasmids (Fraser et al., 1997; Casjens et al., 2000). One of the "plasmids" is better thought of as a small chromosome 
(Byram et al., 2004). Second, B. burgdorferi encodes a large repertoire of lipoproteins, with approximately $7.8 \%$ of the genome encoding known or predicted lipoproteins (Setubal et al., 2006). Some of these lipoproteins have been identified as adhesins, but not all of the adhesins are lipoproteins. Finally, given the comparatively small genome size, a relatively large number of proteins that bind to mammalian or tick cells or extracellular matrix have been identified, and some of these have additional functions that may contribute to the life style of the bacterium.

Various laboratories have shown that Borrelia burgdorferi binds to an array of eukaryotic cells in vitro (Coburn et al., 1993; Comstock et al., 1993; Hechemy et al., 1989; Thomas and Comstock, 1989) and to components of the extracellular matrix (Guo et al., 1995; Leong et al., 1995, 1998a, b; Isaacs, 1994). Further studies have identified receptors on the surface of mammalian cells and particular molecules of the extracellular matrix to which the bacteria attach, and the B. burgdorferi proteins that serve as adhesins interacting with these molecules. Table 3.1 lists Borrelia burgdorferi adhesins, both known and candidate ones, as well as additional information on their respective host cell substrates and roles in $B$. burgdorferi infection. In this section, ECM-binding proteins will be reviewed; in later sections, those that bind to molecules specifically expressed on the mammalian cell surface, and those that bind to unknown substrates, will be described.

\subsection{Borrelia burgdorferi Proteins That Promote Interaction with the Extracellular Matrix}

\subsubsection{Attachment to Fibronectin}

Fibronectin (Fn) is present in both soluble and insoluble extracellular matrix forms, and is targeted by many bacterial adhesins due to its ubiquity, its multiple distinct functional binding domains, and its ability to interact with multiple substrates. These may also assist bacterial pathogens in establishment of infection. In normal physiology, Fn binds to several integrins and to other extracellular matrix components including collagen, fibrinogen and some proteoglycans. It plays a major role in cell adhesion, growth, migration and differentiation, and it is important for processes such as wound healing and embryonic development (reviewed in Kadler et al., 2008).

B. burgdorferi produces several Fn-binding adhesins (Table 3.1). Early work suggesting Fn binding activity by Szczepanski et al. (1990) and Grab et al. (1998) led to the identification of the best-characterized Fn-binding adhesin of B. burgdorferi, BBK32 (Probert and Johnson, 1998). The Fn-binding region of BBK32 was identified as a region of 32 amino acids that was common to all Borrelia strains tested (Probert et al., 2001). Elegant structurefunction analyses revealed that BBK32 shares a mechanism of binding to Fn with Fnbinding adhesins of the Gram-positive pathogens Staphylocccus aureus and Streptococcus pyogenes (Probert et al., 2001; Raibaud et al., 2005). It also promotes the aggregation of plasma Fn to superFn (a higher order multimer of fibronectin) (Prabhakaran et al., 2009), supporting a role for this and other specific bacterial adhesins that goes beyond simple attachment. BBK32 is expressed by B. burgdorferi as the tick feeds and while the bacteria are in the mammalian host (Fikrig et al., 2000). Consistent with this pattern of expression, 
deletion of $b b k 32$ increases the $\mathrm{ID}_{50}$ in mice (Seshu et al., 2006), but at high dose does not significantly attenuate virulence or tick colonization (Li et al., 2006).

Given that BBK32 deficient mutant strains still bind Fn, the identification of additional Fnbinding proteins came as no surprise. In fact, three additional Fn-binding proteins have been identified (Brissette et al., 2009a). The first of these proteins, RevA, was previously studied by other groups on the basis of differential gene expression in mammalian versus tick environments (Gilmore and Mbow, 1998; Carroll et al., 2001). In some B. burgdorferi strains, a second copy of revA is present on a different plasmid. A related gene, $\operatorname{rev} B$, has also been identified and, like recombinant RevA, recombinant RevB also binds Fn. RevA binds Fn with a slightly lower affinity than BBK32, but the affinity of RevB binding to Fn has yet to be determined (Brissette et al., 2009a). Experimental evidence for RevB binding indicates a more complex interaction with Fn in contrast to the dose-dependent binding of RevA to Fn (Brissette et al., 2009a). In addition, the function of a gene annotated in the genome sequence as encoding a putative Fn-binding protein, bb0347, has not been experimentally addressed. In the future, generation of B. burgdorferi strains in which the genes encoding Fn-binding proteins are inactivated could illuminate the roles of all of these proteins in the life cycle of $B$. burgdorferi.

\subsubsection{Attachment to Decorin}

Decorin is a proteoglycan that consists of a protein core composed of leucine rich repeats, and a glycosaminoglycan (GAG) chain consisting of either chondroitin sulphate or dermatan sulphate depending on the tissue in which it is expressed (Mcewan et al., 2006). Decorin is a component of connective tissue, binds to type I collagen and Fn and plays a role in matrix assembly. In addition to playing a role in the formation of the structural components of the extracellular matrix, the decorin core protein functions as a signaling mediator by interacting with the epidermal growth factor receptor (reviewed in Seidler and Dreier, 2008).

Due to the observations by several groups that $B$. burgdorferi is frequently seen in connective tissues in infected mammals and apparently in contact with collagen fibers, early investigations focused on direct adhesion to collagen. When no direct attachment to immobilized collagen was observed, attachment of the bacteria to the collagen-associated decorin was investigated. Two decorin-binding adhesins (DbpA and DbpB) were identified; the proteins are encoded on one of the linear plasmids in a bicistronic operon (Guo et al., 1998, 1995). A $d b p A B$ mutant was deficient in colonization of the skin and other tissues, even in mice lacking adaptive immunity, suggesting that DbpA and DbpB proteins help the bacteria adhere to multiple tissues and are required for successful interactions with both innate and adaptive immune mechanisms (Weening et al., 2008). Both proteins were found to be important for the virulence of Borrelia burgdorferi in mice, yet contribute differently to colonisation and dissemination to various tissues (Shi et al., 2008a, b). Consistent with this, DbpA and DbpB also have distinct in vitro adhesion activities (Fischer et al., 2003). While the initial studies suggested that the Dbps require the intact proteoglycan for adhesion, subsequent studies indicated that these proteins also bind to glycosaminoglycans (GAGs) in the absence of the core protein (Fischer et al., 2003; Guo et al., 1995). Lysine residues (Lys-82, Lys-163, Lys-170) critical for decorin binding have been identified 
(Brown et al., 1999; Pikas et al., 2003). The decorin-binding activity is uniquely tractable to investigation from the host perspective, as decorin-deficient mice were actually the first mutants used to investigate the role of any candidate virulence factors in B. burgdorferi. In decorin deficient mice, there were fewer bacteria present in hind tibiotarsal joints at low doses of the bacteria, and the arthritis was less severe (Brown et al., 2001).

Later work by a different group showed that $B$. burgdorferi does, in fact, bind to type 1 collagen lattices (Zambrano et al., 2004). This work highlights the importance of the purification methods in determining whether bacterial adhesion occurs to a particular substrate. Extracellular matrix proteins have limited solubility, and the plasma forms of some of these proteins, while soluble, may behave differently. At this point, the adhesin(s) responsible for collagen binding remain unknown.

\subsubsection{Attachment to Glycosaminoglycans}

While decorin is a proteoglycan, additional evidence for a more generalized proteoglycan (PG) binding activity of $B$. burgdorferi was also established. Binding to PGs accounts for some, but not all, of the $B$. burgdorferi cell attachment activity, depending on the cell line and bacterial strain examined. The PG-binding activity is largely determined by recognition of glycosaminoglycan (GAG) chains (Leong et al., 1995, 1998a, b). A Borrelia glycosaminoglycan binding protein (Bgp) was identified by Parveen and colleagues (Parveen and Leong, 2000) and shown to be surface-exposed in intact bacteria. The recombinant protein agglutinates erythrocytes, binds to the same glycosaminoglycans as whole bacteria, and competitively inhibits binding of $B$. burgdorferi to mammalian cells. Another previously identified B. burgdorferi adhesin, BBK32, which binds to Fn, was also found to bind to purified preparations of dermatan sulphate and heparin (Fischer et al., 2006). The fact that exogenous heparin had no effect on the binding affinity of the BBK32expressing bacteria to Fn suggested that BBK32 can bind to multiple molecules independently, or that binding to soluble heparin is relatively weak. Different $B$. burgdorferi strains have different cell- and GAG-binding preferences, and binding to various cell types depends in part on the GAGs they express (Parveen and Leong, 2000). Host-adapted spirochetes show enhanced binding to GAGs (Parveen et al., 2003) suggesting their importance during in vivo infection. However, Bgp, BBK32, and DbpAB mutants of $B$. burgdorferi are all infectious in mice (Seshu et al., 2006; Shi et al., 2008a; Blevins et al., 2008; Weening et al., 2008; Parveen et al., 2006) although in some cases slightly attenuated, suggesting that these different proteins may be functionally redundant.

\subsubsection{Attachment to Laminin}

Laminin is a trimeric glycoprotein that is a component of extracellular matrices, playing an integral role in forming structural scaffolding in almost every tissue. Attachment to laminin has been demonstrated for many bacterial pathogens, including B. burgdorferi. The four paralogous Bmp proteins were found to bind laminin (Verma et al., 2009), as was one of the Erps (OpsE-related proteins, see below), ErpX (Brissette et al., 2009b). The four bmp genes are located on the chromosome and, although they are arranged in a cluster, they are differentially regulated (Bryksin et al., 2005; Dobrikova et al., 2001). Two have been shown to contribute to the development of arthritis in the mouse model of infection (Pal et al., 
2008). One of the Bmp proteins, BmpD, was selected for binding to vascular endothelium in mice by in vivo phage display (Antonara et al., 2007). Since laminin is a basement membrane protein, BmpD may also recognize additional mammalian substrates. The fragment of BmpD that was selected, however, contained sequences $3^{\prime}$ of the stop codon of the allele in the sequenced strain, B31. Thus it is possible that this fragment is available for binding mammalian substrates only in certain strains.

\subsubsection{Erps and CRASPs: Binding to Complement-Regulatory Proteins Factor $\mathbf{H}$ and FHL}

It has been shown that a large family of outer surface proteins, the Erps, is involved in the binding of host proteins. The Erps are encoded by a large multi-gene family, with different erp genes encoded on different plasmids, particularly the cp32 family of plasmids. In earlier literature in the field, these genes were known as uhb (upstream homology box) genes, due to the highly homologous 5' non-coding regions (Marconi et al., 1996; Sung et al., 1998). Indeed, the Erp genes appear to be expressed in similar patterns, although there may be variations in timing and tissue-specific expression in some cases (Mcdowell et al., 2001; Stevenson, 2002). The Erp proteins can be divided into different functional categories: ErpX, which binds laminin, several that bind complement factor $\mathrm{H}$ and related complement regulators, and those for which adhesion activity has been demonstrated but the substrate(s) remain undefined. In general, Erp proteins are expressed during mammalian infection but are repressed during colonization of the tick (reviewed in Brissette et al., 2008).

The ErpA, ErpC and ErpP from various Borrelia burgdorferi strains (Alitalo et al., 2002; Hellwage et al., 2001; Metts et al., 2003) show significant affinity for factor $\mathrm{H}$. Factor $\mathrm{H}$ is a complement regulatory protein that circulates in the human plasma and is bound to host cells, and protects host cells from attack by the complement system. Other bacteria have been shown to bind to factor $\mathrm{H}$ and in that way evade the complement activation which can lead to killing of the bacteria by opsonization (reviewed in Sjöberg et al., 2009). In addition, binding of factor $\mathrm{H}$ can help bacteria adhere to host cells since it binds to glycosaminoglycans that are present on the surface of cells (Brissette et al., 2008).

Complement regulator acquiring surface protein (CRASP)-1 and -2 function to evade the host immune system by binding components of the host immune system, factor H-like protein 1(FHL-1) and factor H (Alitalo et al., 2001; Hellwage et al., 2001; Kraiczy et al., 2001a, b; Mcdowell et al., 2001; Wallich et al., 2005). FHL-1 is encoded by the same gene as factor $\mathrm{H}$, and has redundant function in controlling the alternative pathway of complement activation within host innate immunity, but has a unique 4 amino acid extension at the C-terminus (Kraiczy et al., 2001b). Both CRASP-1 and -2 bind to a region of factor $\mathrm{H}$ or FHL-1 that is buried in the unbound protein, but exposed when the C-terminal region is bound. Several Erps bind the $\mathrm{C}$-terminal end of factor $\mathrm{H}$, and so it is possible that CRASPs and Erps act in a complementary fashion (reviewed in Brissette et al., 2008). Strains completely deficient in Erps will need to be created in order to test the function of CRASPs alone, and vice versa. Recently, CRASP-1 has been shown to bind additional host components, including Fn, laminin, plasminogen and several types of collagen (Hallstrom et al., 2010). These additional functions expand the role of CRASP-1 beyond evasion of the immune system, and potentially into aiding colonization in the mammalian host. 
In addition, a distinct subset of the Erps, those belonging to the OspF subfamily, were selected by in vivo phage display as candidate adhesins to the vasculature endothelium (Antonara et al., 2007). These are BBM38 (ErpK), BBO39 (ErpL), BBK2.10 and BBS41 (OspG), and none have been shown to bind factor $\mathrm{H}$. Although the Erp proteins that were selected vary in sequence, they share significant common features. A recombinant protein expressing the selected portion of ErpK, which is also common to BBK2.10 and OspG, showed specific binding to the surface of particular cell lines, suggesting that the selected sequence may be responsible for binding of members of the OspF family to the surface of mammalian cells (Antonara et al., 2007).

\subsubsection{Attachment to Mammalian Cell Surface Receptors}

3.2.6.1 Attachment to Integrins-Although some of the substrates for B. burgdorferi attachment discussed above are also associated with the mammalian cell surface, this section will cover those substrates that are specific to the cell surface and not found in the extracellular matrix or body fluids. Integrins are obligate heterodimeric cation-dependent receptors, found on the surface of all mammalian cells except erythrocytes. They consist of two distinct chains: the alpha $(\alpha)$ and beta $(\beta)$ subunits. The specificity of each integrin depends on the combination of the $\alpha$ and $\beta$ subunits, but some bind multiple ligands. As is the case for several other pathogens, $B$. burgdorferi binds to integrins, including $\alpha_{\mathrm{IIb}} \beta_{3}$ (Coburn et al., 1993), $\alpha_{\mathrm{v}} \beta_{3}, \alpha_{5} \beta_{1}$ (Coburn et al., 1998), and $\alpha_{3} \beta_{1}$ (Behera et al., 2006). Different Lyme disease Borrelia burgdorferi strains bind preferentially to different integrins (Coburn et al., 1998). Binding of the bacteria to $\alpha_{3} \beta_{1}$ on chondrocytes activates inflammatory responses in a TLR-independent manner.

The $B$. burgdorferi ligand for the $\beta_{3}$ chain integrins is an outer surface integral membrane protein, P66 (Coburn et al., 1999; Coburn and Cugini, 2003). The principal ligand for integrin $\alpha_{3} \beta_{1}$ appears to be a putative outer surface protein, BBB07. Like intact $B$. burgdorferi, BBB07 stimulates human primary chondrocytes through integrin $\alpha_{3} \beta_{1}$ to secrete proinflammatory cytokines (Behera et al., 2008). While P66 also stimulates proinflammatory responses by chondrocytes, this does not require $\alpha_{3} \beta_{1}$.

\subsubsection{Candidate Mammalian Substrate Adhesins of B. burgdorferi}

Several additional candidate $B$. burgdorferi adhesins have been identified, but not yet validated as adhesins using additional approaches; for example, the putative mammalian receptors have not yet been identified. In each case, however, other work has demonstrated the proteins to be important in B. burgdorferi infection in mammals, specifically. All were enriched after in vivo selection for binding to vascular endothelium in living mice, but adhesion activity has not yet been demonstrated to be critical to their importance in the life of B. burgdorferi. One, OspC, was shown to be critical for B. burgdorferi to establish disseminated infection (Grimm et al., 2004a; Tilly et al., 2006). A second, VlsE, is better known for antigenic variation during infection (Zhang and Norris, 1998a, b; Lawrenz et al., 1999; Lin et al., 2009; Dresser et al., 2009). Finally, BB0210, annotated as Lmp1, was also highly selected, and is required for persistent infection in mice (Yang et al., 2009). 


\subsubsection{Interaction of Borrelia burgdorferi with the Arthropod Host}

As mentioned above, Borrelia burgdorferi spends a large portion of its life cycle in the arthropod host. It has been shown that certain genes are expressed during the mammalian life cycle, and others are expressed when the bacteria are in the tick. Some of the genes expressed in the tick portion of the life cycle encode outer surface proteins, and the roles of the corresponding proteins in the tick have been investigated. One such protein, OspA, was shown to be an adhesin for tick tissues, and to bind to the "tick receptor for OspA" (TROSPA) (Pal et al., 2004). OspA can bind specifically to recombinant TROSPA in vitro, while in vivo studies showed that disruption of TROSPA by RNA interference diminished the ability of the ticks to acquire Borrelia burgdorferi from infected mice (Pal et al., 2004). A small number of $B$. burgdorferi were found to still bind with TROSPA activity abolished, leaving the door open to another adhesin-receptor interaction also mediating binding to the tick midgut.

Consistent with an important role for the life of B. burgdorferi in the tick, ospA, and the other gene in the bicistronic operon, $\operatorname{sp} B$, are expressed when the bacteria leave the mammalian host and enter the feeding tick (Schwan and Piesman, 2000). The importance of these proteins for the maintenance of the bacteria in ticks was demonstrated when $\operatorname{sp} A B$ mutant bacteria that were fully infectious in mice were acquired by ticks, but unable to persist in the tick midgut (Yang et al., 2004). More recent work in the field has demonstrated that a primary role of OspA is protection of the bacteria already residing in the tick midgut from killing by host antibodies as the tick takes in a blood meal (Battisti et al., 2008), which would be critical for maintenance of the infection in the natural cycle between vertebrate animals and ticks.

A salivary protein of Ixodes scapularis ticks, Salp15, was shown to bind to a different $B$. burgdorferi protein, OspC (Ramamoorthi et al., 2005). Binding of the bacteria to Salp15, which inhibits T-cell activation, appeared to inhibit in vitro antibody mediated killing of the bacteria. Nonetheless, Salp15 does not seem to be required for B. burgdorferi to establish infection, since an infection can be established by needle inoculation of the bacteria into mice (Barthold et al., 1988). OspC however, is critical to the ability of B. burgdorferi to establish disseminated infection in mice (Grimm et al., 2004b; Tilly et al., 2006), and was selected as a candidate adhesin for the vascular endothelium in mice using in vivo phage display (Antonara et al., 2007).

\subsection{Concluding Remarks}

Borrelia burgdorferi expresses a number of adhesins, many with redundant functions. This redundancy suggests that these functions are critical to the ability of the bacterium to cause infection in mammals, but testing this hypothesis will require novel approaches, given the difficulties involved in the genetic manipulation of this organism. It will be especially interesting to further investigate $B$. burgdorferi interactions with the tick, which only become more complex as more is learned. It will also be interesting to see how $B$. burgdorferi adhesins interact with their host substrates at the molecular level, as many of the B. burgdorferi proteins have no homologs outside of the genus. With recent advances in 
development of genetic tool sets, the in vivo roles of the B. burgdorferi adhesins should be discernable within the next few years.

\section{References}

Alitalo A, Meri T, Lankinen H, Seppälä I, Lahdenne P, Hefty PS, Akins D, Meri S. Complement inhibitor factor $\mathrm{H}$ binding to Lyme disease spirochetes is mediated by inducible expression of multiple plasmid-encoded outer surface protein E paralogs. J Immunol. 2002; 169:3847-3853. [PubMed: 12244181]

Alitalo A, Meri T, Rämö L, Jokiranta TS, Heikkilä T, Seppälä IJ, Oksi J, Viljanen M, Meri S. Complement evasion by Borrelia burgdorferi : serum-resistant strains promote $\mathrm{C} 3 \mathrm{~b}$ inactivation. Infect Immun. 2001; 69:3685-3691. [PubMed: 11349031]

Antonara S, Chafel RM, LaFrance M, Coburn J. Borrelia burgdorferi adhesins identified using in vivo phage display. Mol Microbiol. 2007; 66:262-276. [PubMed: 17784908]

Bankhead T, Chaconas G. The role of VlsE antigenic variation in the Lyme disease spirochete: persistence through a mechanism that differs from other pathogens. Mol Microbiol. 2007; 65:15471558. [PubMed: 17714442]

Barthold SW, Moody KD, Terwilliger GA, Jacoby RO, Steere AC. An animal model for Lyme arthritis. Ann NY Acad Sci. 1988; 539:264-273. [PubMed: 3263827]

Battisti JM, Bono JL, Rosa PA, Schrumpf ME, Schwan TG, Policastro PF. Outer surface protein A protects Lyme disease spirochetes from acquired host immunity in the tick vector. Infect Immun. 2008; 76:5228-5237. [PubMed: 18779341]

Behera AK, Durand E, Cugini C, Antonara S, Bourassa L, Hildebrand E, Hu LT, Coburn J. Borrelia burgdorferi $B B B 07$ interaction with integrin a $3 \beta 1$ stimulates production of pro-inflammatory mediators in primary human chondrocytes. Cell Microbiol. 2008; 10:320-331. [PubMed: 17822440]

Behera AK, Hildebrand E, Uematsu S, Akira S, Coburn J, Hu LT. Identification of a TLR-independent pathway for Borrelia burgdorferi-induced expression of matrix metalloproteinases and inflammatory mediators through binding to integrin a3 $\beta 1$. J Immunol. 2006; 177:657-664. [PubMed: 16785564]

Blevins JS, Hagman KE, Norgard MV. Assessment of decorin-binding protein A to the infectivity of Borrelia burgdorferi in the murine models of needle and tick infection. BMC Microbiol. 2008; 8:82. [PubMed: 18507835]

Brissette CA, Bykowski T, Cooley AE, Bowman A, Stevenson B. Borrelia burgdorferi RevA antigen binds host fibronectin. Infect Immun. 2009a; 77:2802-2812. [PubMed: 19398540]

Brissette CA, Cooley AE, Burns LH, Riley SP, Verma A, Woodman ME, Bykowski T, Stevenson B. Lyme borreliosis spirochete Erp proteins, their known host ligands, and potential roles in mammalian infection. Int J Med Microbiol. 2008; 298(Suppl 1):257-267. [PubMed: 18248770]

Brissette CA, Verma A, Bowman A, Cooley AE, Stevenson B. The Borrelia burgdorferi outer-surface protein ErpX binds mammalian laminin. Microbiology. 2009b; 155:863-872. [PubMed: 19246757]

Brown EL, Guo BP, O’Neal P, Höök M. Adherence of Borrelia burgdorferi Identification of critical lysine residues in DbpA required for decorin binding. J Biol Chem. 1999; 274:26272-26278. [PubMed: 10473582]

Brown EL, Wooten RM, Johnson BJ, Iozzo RV, Smith A, Dolan MC, Guo BP, Weis JJ, Höök M. Resistance to Lyme disease in decorin-deficient mice. J Clin Invest. 2001; 107:845-852. [PubMed: 11285303]

Bryksin AV, Godfrey HP, Carbonaro CA, Wormser GP, Aguero-Rosenfeld ME, Cabello FC. Borrelia burgdorferi $\mathrm{BmpA}, \mathrm{BmpB}$, and $\mathrm{BmpD}$ proteins are expressed in human infection and contribute to P39 immunoblot reactivity in patients with Lyme disease. Clin Diagn Lab Immunol. 2005; 12:935-940. [PubMed: 16085911]

Byram R, Stewart PE, Rosa P. The essential nature of the ubiquitous 26-kilobase circular replicon of Borrelia burgdorferi . J Bacteriol. 2004; 186:3561-3569. [PubMed: 15150244] 
Carroll JA, El-Hage N, Miller JC, Babb K, Stevenson B. Borrelia burgdorferi RevA antigen is a surface-exposed outer membrane protein whose expression is regulated in response to environmental temperature and pH. Infect Immun. 2001; 69:5286-5293. [PubMed: 11500397]

Casjens S, Palmer N, Van Vugt R, Huang WM, Stevenson B, Rosa P, Lathigra R, Sutton G, Peterson J, Dodson RJ, Haft D, Hickey E, Gwinn M, White O, Fraser CM. A bacterial genome in flux: the twelve linear and nine circular extrachromosomal DNAs in an infectious isolate of the Lyme disease spirochete Borrelia burgdorferi . Mol Microbiol. 2000; 35:490-516. [PubMed: 10672174]

Coburn J, Chege W, Magoun L, Bodary SC, Leong JM. Characterization of a candidate Borrelia burgdorferi beta3-chain integrin ligand identified using a phage display library. Mol Microbiol. 1999; 34:926-940. [PubMed: 10594819]

Coburn J, Cugini C. Targeted mutation of the outer membrane protein P66 disrupts attachment of the Lyme disease agent, Borrelia burgdorferi to integrin alphavbeta3. Proc Natl Acad Sci USA. 2003; 100:7301-7306. [PubMed: 12748384]

Coburn J, Leong JM, Erban JK. Integrin alpha IIb beta 3 mediates binding of the Lyme disease agent Borrelia burgdorferi to human platelets. Proc Natl Acad Sci USA. 1993; 90:7059-7063. [PubMed: 8394007]

Coburn J, Magoun L, Bodary SC, Leong JM. Integrins av $\beta 3$ and a5 $\beta 1$ mediate attachment of Lyme disease spirochetes to human cells. Infect Immun. 1998; 66:1946-1952. [PubMed: 9573074]

Comstock LE, Fikrig E, Shoberg RJ, Flavell RA, Thomas DD. A monoclonal antibody to OspA inhibits association of Borrelia burgdorferi with human endothelial cells. Infect Immun. 1993; 61:423-431. [PubMed: 7678585]

Dobrikova EY, Bugrysheva J, Cabello FC. Two independent transcriptional units control the complex and simultaneous expression of the bmp paralogous chromosomal gene family in Borrelia burgdorferi . Mol Microbiol. 2001; 39:370-379. [PubMed: 11136458]

Dresser AR, Hardy PO, Chaconas G. Investigation of the genes involved in antigenic switching at the vlsE locus in Borrelia burgdorferi : an essential role for the RuvAB branch migrase. PLoS Pathog. 2009; 5:e1000680. [PubMed: 19997508]

Fikrig E, Feng W, Barthold SW, Telford SR 3rd, Flavell RA. Arthropod- and host-specific Borrelia burgdorferi bbk32 expression and the inhibition of spirochete transmission. J Immunol. 2000; 164:5344-5351. [PubMed: 10799897]

Fischer JR, LeBlanc KT, Leong JM. Fibronectin binding protein BBK32 of the Lyme disease spirochete promotes bacterial attachment to glycosaminoglycans. Infect Immun. 2006; 74:435441. [PubMed: 16368999]

Fischer JR, Parveen N, Magoun L, Leong JM. Decorin-binding proteins A and B confer distinct mammalian cell type-specific attachment by Borrelia burgdorferi the Lyme disease spirochete. Proc Natl Acad Sci USA. 2003; 100:7307-7312. [PubMed: 12773620]

Fraser CM, Casjens S, Huang WM, Sutton GG, Clayton R, Lathigra R, White O, Ketchum KA, Dodson R, Hickey EK, Gwinn M, Dougherty B, Tomb JF, Fleischmann RD, Richardson D, Peterson J, Kerlavage AR, Quackenbush J, Salzberg S, Hanson M, Van Vugt R, Palmer N, Adams MD, Gocayne J, Venter JC, et al. Genomic sequence of a Lyme disease spirochaete, Borrelia burgdorferi . Nature. 1997; 390:580-586. [PubMed: 9403685]

Gilmore RD Jr, Mbow ML. A monoclonal antibody generated by antigen inoculation via tick bite is reactive to the Borrelia burgdorferi Rev protein, a member of the 2.9 gene family locus. Infect Immun. 1998; 66:980-986. [PubMed: 9488385]

Grab DJ, Givens C, Kennedy R. Fibronectin-binding activity in Borrelia burgdorferi . Biochim Biophys Acta. 1998; 1407:135-145. [PubMed: 9685613]

Grimm D, Eggers CH, Caimano MJ, Tilly K, Stewart PE, Elias AF, Radolf JD, Rosa PA. Experimental assessment of the roles of linear plasmids lp25 and lp28-1 of Borrelia burgdorferi throughout the infectious cycle. Infect Immun. 2004a; 72:5938-5946. [PubMed: 15385497]

Grimm D, Tilly K, Byram R, Stewart PE, Krum JG, Bueschel DM, Schwan TG, Policastro PF, Elias AF, Rosa PA. Outer-surface protein $\mathrm{C}$ of the Lyme disease spirochete: a protein induced in ticks for infection of mammals. Proc Natl Acad Sci USA. 2004b; 101:3142-3147. [PubMed: 14970347]

Guo BP, Brown EL, Dorward DW, Rosenberg LC, Höök M. Decorin-binding adhesins from Borrelia burgdorferi. Mol Microbiol. 1998; 30:711-723. [PubMed: 10094620] 
Guo BP, Norris SJ, Rosenberg LC, Höök M. Adherence of Borrelia burgdorferi to the proteoglycan decorin. Infect Immun. 1995; 63:3467-3472. [PubMed: 7642279]

Hallström T, Haupt K, Kraiczy P, Hortschansky P, Wallich R, Skerka C, Zipfel PF. Complement regulator-acquiring surface protein 1 of Borrelia burgdorferi binds to human bone morphogenic protein 2, several extracellular matrix proteins, and plasminogen. J Infect Dis. 2010; 202:490-498. [PubMed: 20565259]

Hechemy KE, Samsonoff WA, Mckee M, Guttman JM. Borrelia burgdorferi attachment to mammalian cells. J Infect Dis. 1989; 159:805-806. [PubMed: 2926175]

Hellwage J, Meri T, Heikkilä T, Alitalo A, Panelius J, Lahdenne P, Seppälä IJ, Meri S. The complement regulator factor $\mathrm{H}$ binds to the surface protein OspE of Borrelia burgdorferi . J Biol Chem. 2001; 276:8427-8435. [PubMed: 11113124]

Isaacs RD. Borrelia burgdorferi bind to epithelial cell proteoglycans. J Clin Invest. 1994; 93:809-819. [PubMed: 8113413]

Kadler KE, Hill A, Canty-Laird EG. Collagen fibrillogenesis: fibronectin, integrins, and minor collagens as organizers and nucleators. Curr Opin Cell Biol. 2008; 20:495-501. [PubMed: 18640274]

Kraiczy P, Skerka C, Brade V, Zipfel PF. Further characterization of complement regulator-acquiring surface proteins of Borrelia burgdorferi . Infect Immun. 2001a; 69:7800-7809. [PubMed: 11705962]

Kraiczy P, Skerka C, Kirschfink M, Brade V, Zipfel PF. Immune evasion of Borrelia burgdorferi by acquisition of human complement regulators FHL-1/reconectin and factor H. Eur J Immunol. 2001b; 31:1674-1684. [PubMed: 11385611]

Lawrenz MB, Hardham JM, Owens RT, Nowakowski J, Steere AC, Wormser GP, Norris SJ. Human antibody responses to VlsE antigenic variation protein of Borrelia burgdorferi. J Clin Microbiol. 1999; 37:3997-4004. [PubMed: 10565921]

Leong JM, Morrissey PE, Ortega-Barria E, Pereira ME, Coburn J. Hemagglutination and proteoglycan binding by the Lyme disease spirochete, Borrelia burgdorferi . Infect Immun. 1995; 63:874-883. [PubMed: 7532628]

Leong JM, Robbins D, Rosenfeld L, Lahiri B, Parveen N. Structural requirements for glycosaminoglycan recognition by the Lyme disease spirochete, Borrelia burgdorferi . Infect Immun. 1998a; 66:6045-6048. [PubMed: 9826395]

Leong JM, Wang H, Magoun L, Field JA, Morrissey PE, Robbins D, Tatro JB, Coburn J, Parveen N. Different classes of proteoglycans contribute to the attachment of Borrelia burgdorferi to cultured endothelial and brain cells. Infect Immun. 1998b; 66:994-999. [PubMed: 9488387]

Li X, Liu X, Beck DS, Kantor FS, Fikrig E. Borrelia burgdorferi lacking BBK32, a fibronectinbinding protein, retains full pathogenicity. Infect Immun. 2006; 74:3305-3313. [PubMed: 16714558]

Lin T, Gao L, Edmondson DG, Jacobs MB, Philipp MT, Norris SJ. Central role of the holliday junction helicase RuvAB in vlsE recombination and infectivity of Borrelia burgdorferi . PLoS Pathog. 2009; 5:e1000679. [PubMed: 19997622]

Marconi RT, Sung SY, Hughes CA, Carlyon JA. Molecular and evolutionary analyses of a variable series of genes in Borrelia burgdorferi that are related to ospE and ospF, constitute a gene family, and share a common upstream homology box. J Bacteriol. 1996; 178:5615-5626. [PubMed: 8824605]

McDowell JV, Sung SY, Price G, Marconi RT. Demonstration of the genetic stability and temporal expression of select members of the Lyme disease spirochete OspF protein family during infection in mice. Infect Immun. 2001; 69:4831-4838. [PubMed: 11447157]

McEwan PA, Scott PG, Bishop PN, Bella J. Structural correlations in the family of small leucine-rich repeat proteins and proteoglycans. J Struct Biol. 2006; 155:294-305. [PubMed: 16884925]

Metts MS, McDowell JV, Theisen M, Hansen PR, Marconi RT. Analysis of the OspE determinants involved in binding of factor $\mathrm{H}$ and OspE-targeting antibodies elicited during Borrelia burgdorferi infection in mice. Infect Immun. 2003; 71:3587-3596. [PubMed: 12761144] 
Norman MU, Moriarty TJ, Dresser AR, Millen B, Kubes P, Chaconas G. Molecular mechanisms involved in vascular interactions of the Lyme disease pathogen in a living host. PLoS Pathog. 2008; 4:e1000169. [PubMed: 18833295]

Pal U, Li X, Wang T, Montgomery RR, Ramamoorthi N, Desilva AM, Bao F, Yang X, Pypaert M, Pradhan D, Kantor FS, Telford S, Anderson JF, Fikrig E. TROSPA, an Ixodes scapularis receptor for Borrelia burgdorferi . Cell. 2004; 119:457-468. [PubMed: 15537536]

Pal U, Wang P, Bao F, Yang X, Samanta S, Schoen R, Wormser GP, Schwartz I, Fikrig E. Borrelia burgdorferi basic membrane proteins $\mathrm{A}$ and $\mathrm{B}$ participate in the genesis of Lyme arthritis. J Exp Med. 2008; 205:133-141. [PubMed: 18166585]

Parveen N, Caimano M, Radolf JD, Leong JM. Adaptation of the Lyme disease spirochaete to the mammalian host environment results in enhanced glycosaminoglycan and host cell binding. Mol Microbiol. 2003; 47:1433-1444. [PubMed: 12603746]

Parveen N, Cornell KA, Bono JL, Chamberland C, Rosa P, Leong JM. Bgp, a secreted glycosaminoglycan-binding protein of Borrelia burgdorferi strain N40, displays nucleosidase activity and is not essential for infection of immunodeficient mice. Infect Immun. 2006; 74:30163020. [PubMed: 16622242]

Parveen N, Leong JM. Identification of a candidate glycosaminoglycan-binding adhesin of the Lyme disease spirochete Borrelia burgdorferi . Mol Microbiol. 2000; 35:1220-1234. [PubMed: 10712702]

Pikas DS, Brown EL, Gurusiddappa S, Lee LY, Xu Y, Höök M. Decorin-binding sites in the adhesin DbpA from Borrelia burgdorferi : a synthetic peptide approach. J Biol Chem. 2003; 278:30920 30926. [PubMed: 12761224]

Prabhakaran S, Liang X, Skare JT, Potts JR, Höök M. A novel fibronectin binding motif in MSCRAMMs targets F3 modules. PLoS One. 2009; 4:e5412. [PubMed: 19404402]

Probert WS, Johnson BJ. Identification of a $47 \mathrm{kDa}$ fibronectin-binding protein expressed by Borrelia burgdorferi isolate B31. Mol Microbiol. 1998; 30:1003-1015. [PubMed: 9988477]

Probert WS, Kim JH, Höök M, Johnson BJB. Mapping the ligand-binding region of the Borrelia burgdorferi fibronectin-binding protein BBK32. Infect Immun. 2001; 69:4129-4133. [PubMed: 11349087]

Raibaud S, Schwarz-Linek U, Kim JH, Jenkins HT, Baines ER, Gurusiddappa S, Höök M, Potts JR. Borrelia burgdorferi binds fibronectin through a tandem beta-zipper, a common mechanism of fibronectin binding in staphylococci, streptococci, and spirochetes. J Biol Chem. 2005; 280:18803-18809. [PubMed: 15737988]

Ramamoorthi N, Narasimhan S, Pal U, Bao F, Yang XF, Fish D, Anguita J, Norgard MV, Kantor FS, Anderson JF, Koski RA, Fikrig E. The Lyme disease agent exploits a tick protein to infect the mammalian host. Nature. 2005; 436:573-577. [PubMed: 16049492]

Saidac DS, Marras SA, Parveen N. Detection and quantification of Lyme spirochetes using sensitive and specific molecular beacon probes. BMC Microbiol. 2009; 9:43. [PubMed: 19239692]

Schwan TG, Piesman J. Temporal changes in outer surface proteins A and C of the Lyme diseaseassociated spirochete, Borrelia burgdorferi during the chain of infection in ticks and mice. J Clin Microbiol. 2000; 38:382-388. [PubMed: 10618120]

Seidler DG, Dreier R. Decorin and its galactosaminoglycan chain: extracellular regulator of cellular function? IUBMB Life. 2008; 60:729-733. [PubMed: 18800386]

Seshu J, Esteve-Gassent MD, Labandeira-Rey M, Kim JH, Trzeciakowski JP, Höök M, Skare JT. Inactivation of the fibronectin-binding adhesin gene bbk32 significantly attenuates the infectivity potential of Borrelia burgdorferi . Mol Microbiol. 2006; 59:1591-1601. [PubMed: 16468997]

Setubal JC, Reis M, Matsunaga J, Haake DA. Lipoprotein computational prediction in spirochaetal genomes. Microbiology. 2006; 152:113-121. [PubMed: 16385121]

Shi Y, Xu Q, McShan K, Liang FT. Both decorin-binding proteins A and B are critical for the overall virulence of Borrelia burgdorferi . Infect Immun. 2008a; 76:1239-1246. [PubMed: 18195034]

Shi Y, Xu Q, Seemanaplli SV, McShan K, Liang FT. Common and unique contributions of decorinbinding proteins A and B to the overall virulence of Borrelia burgdorferi . PLoS One. 2008b; 3:e3340. [PubMed: 18833332] 
Sjöberg AP, Trouw LA, Blom AM. Complement activation and inhibition: a delicate balance. Trends Immunol. 2009; 30:83-90. [PubMed: 19144569]

Stevenson B. Borrelia burgdorferi erp (ospE-related) gene sequences remain stable during mammalian infection. Infect Immun. 2002; 70:5307-5311. [PubMed: 12183589]

Sung SY, Lavoie CP, Carlyon JA, Marconi RT. Genetic divergence and evolutionary instability in ospE-related members of the upstream homology box gene family in Borrelia burgdorferi sensu lato complex isolates. Infect Immun. 1998; 66:4656-4668. [PubMed: 9746562]

Szczepanski A, Furie MB, Benach JL, Lane BP, Fleit HB. Interaction between Borrelia burgdorferi and endothelium in vitro. J Clin Invest. 1990; 85:1637-1647. [PubMed: 2332509]

Thomas DD, Comstock LE. Interaction of Lyme disease spirochetes with cultured eukaryotic cells. Infect Immun. 1989; 57:1324-1326. [PubMed: 2925254]

Tilly K, Bestor A, Jewett MW, Rosa P. Rapid clearance of lyme disease spirochetes lacking OspC from skin. Infect Immun. 2007; 75:1517-1519. [PubMed: 17158906]

Tilly K, Krum JG, Bestor A, Jewett MW, Grimm D, Bueschel D, Byram R, Dorward D, Vanraden MJ, Stewart P, Rosa P. Borrelia burgdorferi OspC protein required exclusively in a crucial early stage of mammalian infection. Infect Immun. 2006; 74:3554-3564. [PubMed: 16714588]

Verma A, Brissette CA, Bowman A, Stevenson B. Borrelia burgdorferi BmpA is a laminin-binding protein. Infect Immun. 2009; 77:4940-4946. [PubMed: 19703983]

Wallich R, Pattathu J, Kitiratschky V, Brenner C, Zipfel PF, Brade V, Simon MM, Kraiczy P. Identification and functional characterization of complement regulator-acquiring surface protein 1 of the Lyme disease spirochetes Borrelia afzelii and Borrelia garinii . Infect Immun. 2005; 73:2351-2359. [PubMed: 15784581]

Weening EH, Parveen N, Trzeciakowski JP, Leong JM, Höök M, Skare JT. Borrelia burgdorferi lacking DbpBA exhibits an early survival defect during experimental infection. Infect Immun. 2008; 76:5694-5705. [PubMed: 18809667]

Xu Q, McShan K, Liang FT. Verification and dissection of the ospC operator by using flaB promoter as a reporter in Borrelia burgdorferi . Microb Pathog. 2008; 45:70-78. [PubMed: 18479884]

Yang X, Coleman AS, Anguita J, Pal U. A chromosomally encoded virulence factor protects the Lyme disease pathogen against host-adaptive immunity. PLoS Pathog. 2009; 5:e1000326. [PubMed: 19266024]

Yang XF, Pal U, Alani SM, Fikrig E, Norgard MV. Essential role for OspA/B in the life cycle of the Lyme disease spirochete. J Exp Med. 2004; 199:641-648. [PubMed: 14981112]

Zambrano MC, Beklemisheva AA, Bryksin AV, Newman SA, Cabello FC. Borrelia burgdorferi binds to, invades, and colonizes native type I collagen lattices. Infect Immun. 2004; 72:3138-3146. [PubMed: 15155615]

Zhang JR, Norris SJ. Genetic variation of the Borrelia burgdorferi gene vlsE involves cassettespecific, segmental gene conversion. Infect Immun. 1998a; 66:3698-3704. [PubMed: 9673251]

Zhang JR, Norris SJ. Kinetics and in vivo induction of genetic variation of vlsE in Borrelia burgdorferi [erratum appears in Infect Immun 1999 67: 468]. Infect Immun. 1998b; 66:3689-3697. [PubMed: 9673250] 


\section{Table 3.1}

Known and candidate Borrelia burgdorferi adhesins

\begin{tabular}{|c|c|}
\hline Adhesin (genomic locus) & Comments, references \\
\hline \multicolumn{2}{|c|}{ Adhesins that bind to mammalian extracellular matrix components } \\
\hline Bgp $(b b 0588)$ & $\begin{array}{l}\text { Binds to GAGs in vitro (Parveen and Leong, 2000), mutant is infectious in mice but shows some } \\
\text { deficiency in tissue colonization (Parveen et al., 2006; Saidac et al., 2009), may also bind cell cell- } \\
\text { surface proteoglycans }\end{array}$ \\
\hline DbpA $(b b A 24)$ & $\begin{array}{l}\text { Binds to decorin and GAGs in vitro (Fischer et al., 2003; Guo et al., 1998), adhesion specificity is } \\
\text { different from that of DbpB, } d b p B A \text { mutants are attenuated in murine infection (Blevins et al., 2008; } \\
\text { Shi et al., 2008a; Weening et al., 2008) }\end{array}$ \\
\hline DbpB $(b b A 25)$ & $\begin{array}{l}\text { Binds to decorin and GAGs in vitro (Fischer et al., 2003; Guo et al., 1998), binding specificity is } \\
\text { different from that of DbpA, } d b p B A \text { mutants are attenuated in murine infection (Blevins et al., 2008; } \\
\text { Shi et al., 2008a; Weening et al., 2008) }\end{array}$ \\
\hline BBK32 ( $b b K 32)$ & $\begin{array}{l}\text { Binds to fibronectin and GAGs in vitro (Fischer et al., 2006; Probert and Johnson, 1998), these } \\
\text { activities are important for B. burgdorferi interactions with the vasculature in vivo (Norman et al., } \\
\text { 2008), bbk32 mutants are attenuated in murine infection (Seshu et al., 2006) }\end{array}$ \\
\hline $\begin{array}{l}\operatorname{RevA}(b b M 27 \& b b P 27) \\
\quad \operatorname{RevB}(b b C 10)\end{array}$ & $\begin{array}{l}\text { Binds to fibronectin and laminin in vitro, some strains have two copies of the gene; there is a related } \\
\text { gene }(\operatorname{rev} B) \text { that is present only in some B. burgdorferi strains (Brissette et al., 2009a) }\end{array}$ \\
\hline $\begin{array}{l}\text { Bmp family members } \\
\text { A,B,C,D }(b b 0382-0385) \\
\text { ErpX }(\boldsymbol{b} \boldsymbol{b} Q \mathbf{Q 4 7})\end{array}$ & $\begin{array}{l}\text { Bind to laminin in vitro (Verma et al., 2009); D was selected in vivo for adherence to vascular } \\
\text { endothelium in living mice (Antonara et al., 2007); contributes to chronic joint infection (Pal et al., } \\
\text { 2008) } \\
\text { ErpX binds to laminin (Brissette et al., 2009b) }\end{array}$ \\
\hline $\begin{array}{l}\text { Erps: ErpA }(b b P 38, b b I 39), \text { ErpC, } \\
\text { ErpP }(b b N 38) \\
\text { CRASPs: CRASP-1 (CspA, bbA68), } \\
\text { CRASP-2 (CspZ, bbHO6), } \\
\text { CRASP-3=ErpP, CRASP-4=ErpC, } \\
\text { CRASP-5=ErpA }\end{array}$ & $\begin{array}{l}\text { Bind to factor H and/or FHR-1 (factor H related) and/or FHL (factor H-like) (Alitalo et al., 2002; } \\
\text { Hellwage et al., 2001; Metts et al., 2003) }\end{array}$ \\
\hline
\end{tabular}

Adhesins that bind to mammalian cell surface receptors

P66 (bb0603)

Binds to integrins $\alpha_{\mathrm{II}} \beta_{3}$ and $\alpha_{\mathrm{v}} \beta_{3}$ (Coburn et al., 1999), knockout mutant is severely attenuated in mice but not in ticks (Coburn lab, unpublished data)

BBB07 ( $b$ bB07) Binds to $\beta 1$ integrins, stimulates proinflammatory signaling in chondrocytes (Behera et al., 2008)

Adhesins that bind to unidentified mammalian substrates (until further characterization is completed, these remain candidate adhesins)

Lmp1 ( $b$ b0210)

Required for persistence and induction of disease manifestations in immunocompetent mice (Yang et al., 2009), selected in vivo for adherence to vascular endothelium in living mice (Antonara et al., 2007), host substrate(s) unknown

OspC (bbB19)

Essential for initiation of infection in mammals (Grimm et al., 2004b; Tilly et al., 2006, 2007) and for colonization of certain tissues (Xu et al., 2008), selected in vivo for adherence to vascular endothelium in living mice (Antonara et al., 2007), binds to cells in vitro, host substrate(s) unknown

VlsE ( $b b F 32)$

Required for persistent infection in mammals; (Dresser et al., 2009; Bankhead and Chaconas, 2007; Lin et al., 2009) selected in vivo for adherence to vascular endothelium in living mice (Antonara et al., 2007), binds to cells in vitro, host substrate(s) unknown

OspF family members: ErpK

(bbM38),

ErpL (bbO39), OspG (bbS41), OspF

OspF family members, all selected in vivo for adherence to vascular endothelium in living mice

(bbR42)

(Antonara et al., 2007), host substrate(s) unknown

Adhesins that bind to tick substrates

OspA (bbA15)

Binds to TROSPA (tick receptor for OspA) (Pal et al., 2004)

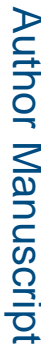

OspC $(b b B 19)$

Binds to Salp15 (Ramamoorthi et al., 2005) 